\title{
Introduction to the Special Section: Cross-Cultural Beliefs, Attitudes, and Dilemmas About Vaccination
}

\author{
Irina Todorova
}

Published online: 9 January 2014

(C) International Society of Behavioral Medicine 2014

Vaccination is one of the most successful public health interventions [1] which has led to the virtual eradication of some infectious diseases through individual and population immunity and is also an area of concern and contestation. Vaccination programs have demonstrated success and are also contested or rejected by members of the public and sometimes the medical profession. This is especially relevant for more recent vaccines, which might not be perceived as directly tied to protection from life-threatening epidemics. Vaccine scares have intensified, and can have detrimental effects, as seen with the measles, mumps, and rubella (MMR) vaccine with the publication of the a report in the UK [2], which linked the vaccine to autism. Despite the study eventually being retracted, the effects on vaccination rates and attitudes toward vaccination in general were significant and undermined public confidence in vaccines [3]. Recent measles outbreaks across Europe and North America [4, 5], as well reemergence of polio in different parts of the world [6] highlight the effects of under-immunization.

The introduction of more novel vaccines to the public has also been shown to be problematic, such as was the example with the recent human papilloma virus (HPV) vaccine primarily targeted at preadolescent girls prior to sexual debut for protection against infection by the HPV virus. Despite publications assuring its safety [7], the vaccine continues to raise concerns among parents related to safety, parental consent, sexuality, and morality. Vaccination is therefore not a neutral public health intervention but can be seen as a site of controversy - the controversies, dilemmas, and acceptance or

I. Todorova $(\triangle)$

Department of Health Sciences, Northeastern University, Robinson

Hall 209, Boston, MA 02115, USA

e-mail: ilgt1@comcast.net rejection of vaccines have their specific manifestations and meanings in different cultural and historical contexts.

While resistance to pharmaceuticals in general and vaccinations in particular can be rooted in unsubstantiated scares or misinformation, they can also make sense from the perspective of users. People's decisions regarding medication use might not conform to rationalistic understandings, or might seem "irrational," yet make complete sense when considering the situations and symbolic meanings which they have acquired. Pharmaceuticals can have "important symbolic meanings," be relevant to social identities, and be embedded in other social interactions and structures, and thus have "wider social explanations" [8]. As stated by Scherman and Löwhagen, "people have good reasons to be non-compliant" [9].

In one example, an analysis of the resistance to a polio vaccination campaign in Northern Nigeria illustrated the role of distrust [10] regarding this intervention among the population. Adams et al. (2007) interpret this resistance through the "collective memory of racism" and "conquest and exploitation" as well as in demonstrated racism in health institutionsand thus has a foundation that makes it meaningful. Recent work delineating the meanings of the HPV vaccine in Romania [11] and Bulgaria [12] similarly illustrates some of the historical, social, and cultural explanations for the existing fears, distrust, and conspiracy theories with which the introduction of the vaccine in Eastern Europe has been met with.

Vaccines are technologies with complex psychological and cultural dimensions. As new or as existing health technologies, they are situated in different locations and elicit multiple personal and cultural meanings and discourses. These include discourses of responsibility, power, morality, and dimensions of inequalities in access to prevention, information, and health literacy [13]. Furthermore, when the technology is one which 
intersects with sexual health and behavior, as is the new HPV vaccine, it further brings forth and transforms gendered meanings and relationships. Vaccines can illuminate relevant historical legacies around fear, control, blame, responsibility, and knowledge, as well as the specifics of current social and health system changes [11]. An analysis of vaccine introduction and dissemination also illustrates the relevance of the vast array of meanings of different stakeholders: parents, adolescents, health professionals, policy makers, and pharmaceutical companies. Thus, it is important to gain understanding about the meanings of vaccination in different contexts and from the perspectives of different stakeholders.

This intersection of meanings and discourses in different cultural contexts is the focus of our special section for the International Journal of Behavioral Medicine. This special section is based on papers that were first presented at a recent symposium of the European Health Psychology Society Conference, 21-25 August 2012, in Prague, Czech Republic entitled: Beliefs, Attitudes and Dilemmas about Vaccination in a Cross-Cultural Perspective. We bring together four empirical papers, which utilize a variety of qualitative research methodologies with the aim of eliciting and interpreting people's meanings and experiences. Penta and Baban (this issue) [14] explore the online communication about the HPV vaccine in discussion forums in Romania and identify both the preferences for vaccination as well as the existing fear and conspiracy theories, which they analyze from the perspective of their embeddedness in Romanian social, economic, and health system context. Gray Brunton et al. (this issue) [15], in conducting a cross-cultural study about attitudes toward the HPV vaccine among college women in Scotland, Spain, Serbia, and Bulgaria identify and analyze the implications of two common discourses - that of the 'responsible young woman,' and that of 'exclusion.' The paper by Kennedy et al. (this issue) [16] discusses the historical and current doubts about three vaccines-MMR, H1N1, and HPV-in the context of Scotland and the previous vaccine scares. Todorova et al. (this issue) [17] illustrate the nuanced perspectives of health providers in Bulgaria regarding the HPV vaccine, particularly in the context of increasing mortality rates from cervical cancer in the country and provider's sense of responsibility and helplessness to reduce this trend. In summary, the papers illustrate similarities and differences in policies, attitudes, and concerns about vaccines across several countries and age groups, delineated in the discussion paper by Lyons (this issue) [13].

\section{References}

1. World Health Organization. Immunization against diseases of public health importance. Fact sheet no. 288. WHO, 2005

2. Wakefield AJ. MMR vaccination and autism. Lancet. 1999;354: 9182.

3. Poland GA. MMR vaccine and autism: vaccine nihilism and postmodern science. Mayo Clin Proc Mayo Clin. 2011;86(9):869-71. doi:10.4065/mcp.2011.0467.

4. Maltezou HC, Wicker S. Measles in health-care settings. Am J Infect Control. 2013;41(7):661-3. doi:10.1016/j.ajic.2012.09.017.

5. Pereira JA, Quach S, Dao HH, Kwong JC, Deeks SL, Crowcroft NS, et al. Contagious comments: what was the online buzz about the 2011 Quebec measles outbreak? PLoS ONE. 2013;8(5):1-9. doi:10.1371/ journal.pone.0064072.

6. US Centers for Disease Control. Update on vaccine-derived polioviruses-worldwide, April 2011-June 2012. MMWR Morb Mortal Wkly Rep. 2012;61:741-6.

7. Zimet GD, Rosberger Z, Fisher WA, Perez S, Stupiansky NW. Beliefs, behaviors and HPV vaccine: correcting the myths and the misinformation. Prev Med. 2013;57(5):414-8. doi:10.1016/j.ypmed.2013.05.013.

8. Stephens C. Narrative analysis in health psychology research: personal, dialogical, and social stories of health. Health Psychol Rev. 2011;5(1):62-78.

9. Scherman MH, Löwhagen O. Drug compliance and identity: reasons for non-compliance. Experiences of medication from persons with asthma/allergy. Patient Educ Couns. 2004;54(1):3-9.

10. Adams G, Salter PS. Health psychology in African settings: a cultural-psychological analysis. J Health Psychol. 2007;12(3):539 51. doi:10.1177/1359105307076240.

11. Craciun C, Baban A. "Who will take the blame?" Understanding the reasons why Romanian mothers decline HPV vaccination for their daughters. Vaccine. 2012;30(48):6789-93. doi:10.1016/j.vaccine. 2012.09.016.

12. Todorova I. Preventing cancer in men and women: current advances, disparities, contexts and examples from HPV related cancers. Key Note Lecture. 13th International Congress of Behavioral Medicine; Budapest, Hungary 2012.

13. Lyons AC. Morality, responsibility and risk: the importance of alternative perspectives in vaccination research. Int J Behav Med. This issue. doi:10.1007/s12529-013-9357-3.

14. Pența MA, Băban A. Dangerous agent or savior? HPV vaccine representations on online discussion forums in Romania. Int $\mathrm{J}$ Behav Med. This issue. doi:10.1007/s12529-013-9340-z.

15. Gray Brunton C, Farver I, Jäger M, Lenneis A, Parve K, Patarcic D et al. Young women's constructions of the HPV vaccine: a crosscultural, qualitative study in Scotland, Spain, Serbia and Bulgaria. Int J Behav Med. This issue. doi:10.1007/s12529-013-9357-3.

16. Kennedy C, Gray Brunton C, Hogg R. 'Just that little bit of doubt': Scottish parents', teenage girls' and health professionals' views of the MMR, H1N1 and HPV vaccines. Int J Behav Med. This issue. doi: 10.1007/s12529-013-9356-4.

17. Todorova I, Alexandrova-Karamanova A, Panayotova Y, Dimitrova E, Kotzeva T. Managing uncertainty: healthcare professionals' meanings regarding the HPV vaccine. Int J Behav Med. This issue. doi:10. 1007/s12529-013-9343-9. 